\title{
A Well-Researched Book in Search of an Audience: Making Sense of Genes by Kostas Kampourakis
}

\author{
Review of: Making Sense of Genes, by Kostas Kampourakis; 2017; Cambridge \\ University Press (Cambridge, UK); Paperback ISBN: 978-1-10712-813-2
}

Reviewed by Geoffrey D. Findlay*, College of the Holy Cross, Worcester, MA 01610

$M$ aking Sense of Genes is a unique contribution to the genetics education literature. Too short to be a comprehensive textbook and too detailed to serve as a first introduction to the field for a lay audience, the book may best be considered as a commentary for informed readers on the strengths and limitations of genetics. The author, Kostas Kampourakis, is currently a researcher at the University of Geneva, where he teaches courses on biology and society and biology education. Kampourakis is also a prolific writer, having authored or edited a number of texts, many of which are in the same areas as he teaches. This new work is cast in its prologue as the successor to his 2014 book, Understanding Evolution, which was also published by Cambridge University Press and previously reviewed by CBE-Life Sciences Education (LSE) (Elfring, 2016). Kampourakis conceives of this book as being useful to "undergraduate students in biology, medicine, and pharmacy, as well as biology teachers and educators" and "any lay reader who wants an accessible but rigorous introduction to genes" (pp. 9-10). Some of its commentary is also aimed at professional geneticists and urges them to rein in the hype surrounding the field in the popular press. For the readers of $L S E$, in this review, I consider the value of the book as a potential primary or supplemental textbook and as a resource for genetics teachers.

At the College of the Holy Cross, I teach an intermediate-level genetics course for biology majors and a human genetics course for non-science majors who need to fulfill a requirement. I thus read Kampourakis's new book with considerable interest, hoping that it might be an appropriate accompaniment to either course. Unfortunately, I finished Making Sense of Genes with the feeling that it was not the best fit for undergraduate students. As an instructor, however, I found the text to be an erudite, provocative, and worthwhile read. Kampourakis's thorough research alerted me to some fascinating primary literature that I hope to incorporate into future courses. Furthermore, while I disagreed with some of his arguments and his ways of making them, the book has helped me consider how most realistically to present the explanatory value and critical limitations of genetics to my students.

In the prologue, Kampourakis explains that he will focus on examples from human genetics because of their increased interest to students, a reasonable choice for this type of book. Throughout the text, he returns to several themes, all of which serve his goal of giving readers a scientifically realistic sense of what genes can, and cannot, help us understand about biology. In particular, Kampourakis rejects the notion that there can be a "gene for" any particular trait and argues against both genetic determinism and genetic reductionism. His advocacy for these positions often leads him to downplay the importance of genes: at several points, he concludes that genes "do nothing on their own" and cannot by themselves explain any trait. These positions differ from the typical tone of genetics texts. Another notable feature of the book is that Kampourakis dives into the social science and science educational primary literature to examine how genetics concepts are understood by students and lay people.

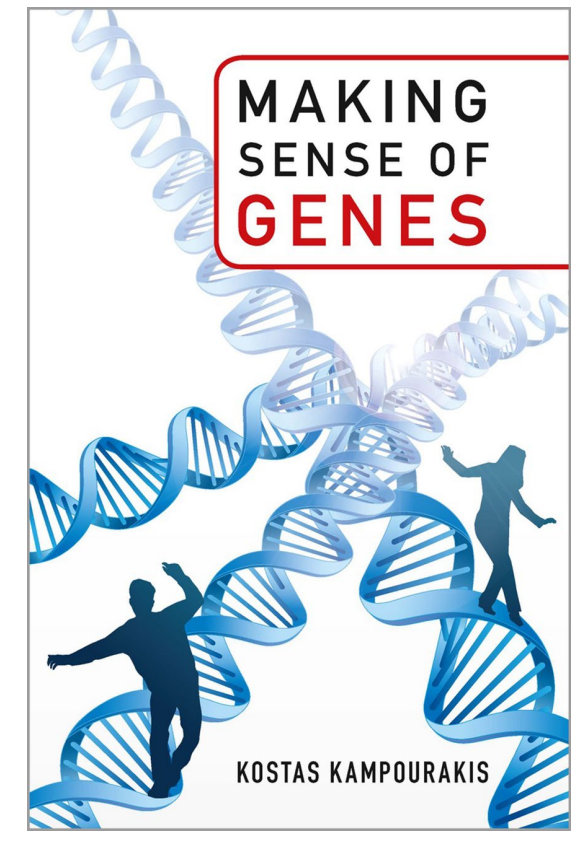

(C) Tim Oliver/Cambridge University Press

CBE Life Sci Educ September 1, 2018 17:fe6 DOI:10.1187/cbe.18-02-0028

*Address correspondence to: Geoffrey D. Findlay (gfindlay@holycross.edu).

(C) 2018 G. D. Findlay. CBE-Life Sciences

Education @ 2018 The American Society for Cell Biology. This article is distributed by The American Society for Cell Biology under license from the author(s). It is available to the public under an Attribution-Noncommercial-Share Alike 3.0 Unported Creative Commons License (http://creativecommons.org/licenses/ by-nc-sa/3.0).

"ASCB®" and "The American Society for Cell Biology®" are registered trademarks of The American Society for Cell Biology. 
Chapters 1-4 trace the historical development of the "gene" idea, from its initial conception as a hereditary entity that contributes toward a physical trait to the more molecular understanding in which genes are DNA segments with many regulatory mechanisms that encode proteins or functional RNAs. Chapter 5 represents a novel contribution, a survey of popular press accounts of genetic studies and examination of educational research on how students (and others) understand genes and genetic determinism. The author also examines how directto-consumer genetic testing companies exploit the public's comfort with genetic determinism to sell their products. This chapter may be particularly worthwhile for instructors teaching a course for non-science majors, as it identifies the typical understandings and misconceptions of new students and the general public. Chapters 6 and 7 dispute the notion that there are "genes for" particular traits or diseases. They explain how genome-wide association studies (GWAS) implicate many loci for traits classically taught as monogenic and discuss examples of complex interactions among genes and between genes and the environment. Chapter 8 revisits direct-to-consumer genetic testing and examines consistencies and inconsistencies in risk estimates between testing platforms, which are used as a springboard for discussing the difficulty of pinpointing which genetic variants are causative of a disease trait. In chapters 9 and 10, Kampourakis argues that how genes affect human traits is best understood by considering their role (and the role of the environment) during development, and how developmental plasticity may confound the predictions made by one's genotype. Finally, in chapters 11 and 12, the author zooms out to talk about the promises and limitations of genome-scale studies. The text concludes with some summarizing remarks, suggestions for further reading, and a thorough bibliography that cites many studies that may be of interest to instructors looking for specific examples for a class. I plan, for example, to integrate some of the author's coverage of GWAS into an upper-level seminar I teach on genomics.

In addition to its deep and thorough research and references, Making Sense of Genes has several other strengths. The author uses effective non-biology analogies in a number of places, an approach that will be helpful to students in understanding some of the more technical content. Kampourakis ends with concrete suggestions for professional scientists to better engage with the public and the media, countering their demonstrated tendency to accept genetic determinism. Reading the book has also prompted me to think more about how best to balance the traditional instructional focus on traits that have, at least in most cases, a relatively simple genetic basis, with counterexamples that are more complex or that depend more on the environment.

Despite these significant strengths, Making Sense of Genes has several weaknesses that would make me shy away from assigning it to undergraduate students. These issues include choices about content, argumentation style, and broader philosophy. In terms of content, unlike a traditional text, a short, narrative work like this cannot be expected to cover the introductory genetics canon comprehensively. Nonetheless, even in the topics Kampourakis chose to include, I noted some important limitations. While he describes interesting population-level data in the context of disease risk assessment, other parts of the book would be strengthened by a greater emphasis on popula- tion genetics (a point I discuss later). While the coverage of genomics is strong in terms of the GWAS popular 5-10 years ago, new sequencing technologies receive little attention, in spite of their growing promise for precision medicine. There is also no mention of CRISPR, though even nonscientists are rapidly becoming familiar with the term; this is an unfortunate oversight for a book published in 2017. More worrisome from an instructional point of view, Kampourakis sometimes adopts definitions that differ from the common standard. In chapter 4, for instance, he defines a gene narrowly to include only the region that is transcribed (pp. 68-69), while most geneticists would include associated regulatory regions as well. He also presents as "problems" for the field issues such as alleles at one gene influencing the expression of alleles at a second gene, ignoring the fact that geneticists already have frameworks to help explain this phenomenon, in this example, epistasis. Finally, I found the book's opening chapter, which focused on the development of the gene concept in the late 19th century, to be too dry to appeal to new students. For instructors interested in highlighting diversity in science, another downside to this historical approach is that it results, in many of the text's early figures, in a parade of headshots of dead men of European descent. The only women to earn photos throughout the whole book are Barbara McClintock and Rosalind Franklin, and the only living scientists depicted are James Watson, Francis Collins, and Craig Venter.

Content is occasionally less accessible to a beginning student through the author's choice of concepts or terms. For example, complex concepts such as mobile genetic elements, copy number variants, and gene imprinting are introduced briefly and inaccessibly in a table (pp. 81-82). A description of alternative splicing is given in the context of T-cell activation (p. 76), and the effects of knocking out the major histocompatibility complex on T-cell selection are detailed (p. 165), both of which make sense only when a reader has some background in immunology.

In terms of argumentation, Kampourakis sometimes uses examples that geneticists would recognize as hyperbolic, but that could be misleading to new students. For instance, Kampourakis emphasizes hypothetical cases in which nontwin siblings share as much as $75-100 \%$ of their genes (p. 193), ignoring the fact that, in humans, independent assortment and recombination consistently yield relatedness values for nontwin siblings that are tightly distributed around 50\% (Visscher et al., 2006). Elsewhere, he uses cases of familial hypercholesterolemia to emphasize the pitfalls that can occur when ascribing health conditions to variants of a single gene (pp. 137-139). The author's broad point is correct, and important: many traits are impacted by a combination of multiple genetic variants interacting with the environment. However, his specific example of a family in which cholesterol levels are impacted by major-effect variants of both the LDLR and PCSK9 genes is unlikely, due to the low allelic frequencies of such variants (Rader et al., 2003; Cohen et al., 2005, 2006). While most traits are indeed influenced by multiple genes (and the environment), when looking across a population, any one family presenting with a genetic condition usually has only one clinically relevant variant. In these instances, greater attention to the population genetics concepts of relatedness and allelic frequencies would be useful. 
Kampourakis ultimately argues that genes "do nothing on their own" (p. 260)—on a semantic level, because they require proteins to be "read," and more broadly, because no trait can be fully explained by a single genetic variant. Instead, Kampourakis argues that the most that can be said of genes is that they influence the development of characters. While it is reasonable to place genes alongside, rather than above, higher-order biological processes, to say that genes "do nothing" (and, in chapters 9 and 10, to argue that genes are best understood only through the lens of development) gives too little credit to genes (and ignores genes that act at only one life stage). After all, if DNA sequences do nothing but impact development, why can the introduction of DNA into cells of a fully developed organ, via gene therapy, cure diseases as severe as blindness (e.g., Maguire et al., 2009)?

The broader issue here may well come down to an instructor's educational philosophy. In choosing a textbook, many instructors opt for a text that presents general rules and then describes exceptions. By contrast, Making Sense of Genes often adopts a contrarian tone, in which the rare counterexample is used to diminish the importance or generalizability of major concepts. While I appreciate Kampourakis's reminders that genetics is not everything and that gene function is complicated, even when a trait is largely influenced by genes, I personally prefer to present to students a more optimistic view of my field. Even for instructors who prefer to advance a robust view of the power of genetics, however, it is important to remain mindful of the limitations in the field. For this reason, I recom- mend Making Sense of Genes to instructors planning a genetics course at any level.

\section{ACKNOWLEDGMENTS}

I thank Mary Lee Ledbetter for many helpful editorial comments. I am supported by a CAREER Award (\#1652013) from the National Science Foundation.

\section{REFERENCES}

Cohen, J. C., Boerwinkle, E., Mosley, T. H., \& Hobbs, H. H. (2006). Sequence variations in PCSK9, low LDL, and protection against coronary heart disease. New England Journal of Medicine, 354, 1264-1272. doi: 10.1056/ NEJMoa054013

Cohen, J., Pertsemlidis, A., Kotowski, I. K., Graham, R., Garcia, C. K., \& Hobbs H. H. (2005). Low LDL cholesterol in individuals of African descent resulting from frequent nonsense mutations in PCSK9. Nature Genetics, 37(3) 161-165. doi: 10.1038/ng1509

Elfring, L. K. (2016). Helping teachers in the evolution-teaching dilemma: Understanding Evolution by Kostas Kampourakis. CBE-Life Sciences Education, 15(4), fe10. doi: 10.1187/cbe.16-09-0283

Maguire, A. M., High, K. A., Auricchio, A., Fraser Wright, J., Pierce, E. A., Testa, F., ... De Baere, E. (2009). Age-dependent effects of RPE65 gene therapy for Leber's congenital amaurosis: A phase 1 dose-escalation trial. Lancet, 374(9701), 1597-1605. https://doi.org/10.1016/S0140-6736(09)61836-5

Rader, D. J., Cohen, J., \& Hobbs, H. H. (2003). Monogenic hypercholesterolemia: New insights in pathogenesis and treatment. Journal of Clinical Investigation, 111(12), 1795-1803. https://doi.org/10.1172/JCl200318925

Visscher, P. M., Medland, S. E., Ferreira, M. A. R., Morley, K. I., Zhu, G., Cornes B. K., ... Martin, N. G. (2006). Assumption-free estimation of heritability from genome-wide identity-by-descent sharing between full siblings. PLoS Genetics, 2(3), e41. https://doi.org/10.1371/journal.pgen.0020041 